\title{
The Sexual Offences Act 2003 and people with mental disorders
}

\author{
Martin Curtice, ${ }^{1}$ Emma Kelson ${ }^{1}$
}

The Psychiatrist (2011), 35, 261-265, doi: 10.1192/pb.bp.110.033076

${ }^{1}$ Moseley Hall Hospital, Birmingham Correspondence to Martin Curtice (mjrc68@doctors.org.uk) First received 14 Oct 2010, accepted 28 Jan 2011

\begin{abstract}
Summary The Sexual Offences Act 2003 repealed and revamped almost all of the existing statute law in relation to sexual offences. The purpose of this was to strengthen and modernise the law in this area. Incorporated within the Act were new and specific offences providing for 'Offences against persons with a mental disorder impeding choice' and offences involving 'Inducement, threat or deception to procure sexual activity with a person with a mental disorder'. Psychiatrists may be involved in such cases to provide assessment and opinion as to whether the alleged victim had a mental disorder and because of this lacked the capacity to consent to sexual activity. Knowledge of the intricacies and implementation of these offences against people with mental disorder can aid clinicians who may be asked to provide expert written and oral evidence and opinion for court cases.
\end{abstract}

Declaration of interest None.
The Sexual Offences Act 2003 emerged following extensive reviews into sexual offences and subsequent recommendations by the government, and replaced the Sexual Offences Act $1956 .^{1-3}$ Before it was introduced, protection for vulnerable groups had been provided by the 1956 Act and the Mental Health Act 1959. Within the 1956 Act there were several offences designed to provide protection to people defined therein as 'defectives'. A 'defective person' was someone 'suffering from a state of arrested or incomplete development of mind which includes severe impairment of intelligence and social functioning'. Such a person was automatically assumed to lack capacity to consent to sexual activity. The Mental Health Act 1959 provided further protection for vulnerable people with specific sexual offences by healthcare staff under Section 128 ('Sexual intercourse with patients'). Section 128(1)(a) made it an offence 'for a man who is an officer on the staff of or is otherwise employed in, or is one of the managers of, a hospital or mental nursing home to have unlawful sexual intercourse with a woman... receiving treatment for mental disorder in that hospital or home, or to have such intercourse on the premises of which the hospital or home forms part with a woman who is... receiving such treatment there as an out-patient'. Section 128(1)(b) provided protection from unlawful sexual intercourse for women with a mental disorder who were subject to guardianship or in a residential home for people with mental disorder. People found guilty under this section were punishable with up to 2 years' imprisonment. Interestingly, under Section 128(2) it would 'not be an offence... for a man to have sexual intercourse with a woman if he does not know and has no reason to suspect her to be a mentally disordered patient.' The Mental Health Act 1983 discarded
Section 128 of the 1959 Act and subsumed 'Ill-treatment of patients' under Section 127. This makes it an offence for healthcare staff to 'ill-treat or wilfully to neglect a patient' who is an in-patient (whether or not detained), out-patient or is under guardianship. In the 2007 revised Mental Health Act, the maximum penalty of imprisonment under Section 127 was increased from 2 to 5 years.

This article describes the construct of the offences against people with a mental disorder under the Sexual Offences Act 2003, analyses case law to elucidate aspects of these offences and considers implications for clinicians who may be involved in providing written or oral evidence in court cases.

\section{The Sexual Offences Act 2003 and offences against people with a mental disorder}

Guidance for Part 1 of the Sexual Offences Act 2003 importantly observes that 'where a person with a mental disorder is able to consent freely to sexual activity' they, of course, 'have the same rights to engage in consensual sexual activity as anyone else'. ${ }^{4}$ Similarly, where such a person did not consent to sexual activity, offences such as rape and sexual assault equally apply to them as to anyone else (the Crown Prosecution Service will decide on which offence to prosecute). The burden will be on the prosecution to prove their case beyond reasonable doubt. Clinicians are most likely to be asked for an expert opinion or assessment as part of the prosecution's case, but the defence legal team could also request such an opinion.

The Act provides for 'Offences against persons with a mental disorder impeding choice' (Sections 30-33) and offences concerning inducement, threat or deception to 
Box 1 Sections of the Sexual Offences Act 2003 that incorporate offences against persons with a mental disorder

30 Sexual activity with a person with a mental disorder impeding choice

31 Causing or inciting a person, with a mental disorder impeding choice, to engage in sexual activity

32 Engaging in sexual activity in the presence of a person with a mental disorder impeding choice

33 Causing a person, with a mental disorder impeding choice, to watch a sexual act

34 Inducement, threat or deception to procure sexual activity with a person with a mental disorder

35 Causing a person with a mental disorder to engage in or agree to engage in sexual activity by inducement, threat or deception

36 Engaging in sexual activity in the presence, procured by inducement, threat or deception, of a person with a mental disorder

37 Causing a person with a mental disorder to watch a sexual act by inducement, threat or deception

Source: Sexual Offences Act 2003.

procure sexual activity with a person with a mental disorder (Sections 34-37). These offences cover a range of inappropriate behaviours, including sexual activity/ touching, causing or inciting sexual activity, engaging in sexual activity in the presence of a person with a mental disorder, causing a person with a mental disorder to watch a sexual act and similar behaviours induced by threat or deception (Box 1). The Act also creates discrete sexual offences by care workers for individuals with a mental disorder (Sections 38-41; for an example, see $R v$. Perera, ${ }^{5}$ where a 59-year-old male nurse was found guilty of sexual activity with a 76-year-old woman who had severe dementia; and $R v$. Bradford, ${ }^{6}$ involving a male social worker and a woman suffering from depression).

In practice, Section 30 is most commonly applied (Box 2), but for all Sections 30-33 there are core issues to be addressed by clinicians who may be asked to produce a statement or report for the court. These are that each offence requires that the defendant (A) acts in respect of another person (B) and that:

- B has a 'mental disorder'

- B must be 'unable to refuse because of or for a reason related to a mental disorder'

- $\mathrm{B}$ is unable to refuse if 'he lacks the capacity to choose whether to agree to the touching (whether because he lacks sufficient understanding of the nature or reasonably foreseeable consequences of what is being done, or for any other reason)' or 'he is unable to communicate such a choice to $A^{\prime}$

- A knows or could reasonably be expected to know that $\mathrm{B}$ has a mental disorder and that because of it or for a reason related to it B is likely to be unable to refuse.
Box 2 Section 30. Sexual activity with a person with a mental disorder impeding choice

(1) A person (A) commits an offence if -

(a) he intentionally touches another person (B),

(b) the touching is sexual,

(c) B is unable to refuse because of or for a reason related to a mental disorder, and

(d) A knows or could reasonably be expected to know that B has a mental disorder and that because of it or for a reason related to it B is likely to be unable to refuse.

(2) B is unable to refuse if -

(a) he lacks the capacity to choose whether to agree to the touching (whether because he lacks sufficient understanding of the nature or reasonably foreseeable consequences of what is being done, or for any other reason), or

(b) he is unable to communicate such a choice to $A$.

(3) A person guilty of an offence under this section, if the touching involved -

(a) penetration of B's anus or vagina with a part of A's body or anything else,

(b) penetration of B's mouth with A's penis,

(c) penetration of A's anus or vagina with a part of B's body, or

(d) penetration of A's mouth with B's penis,

is liable, on conviction on indictment, to imprisonment for life.

(4) Unless subsection (3) applies, a person guilty of an offence under this section is liable -

(a) on summary conviction, to imprisonment for a term not exceeding 6 months or to a fine not exceeding the statutory maximum or both:

(b) on conviction on indictment, to imprisonment for a term not exceeding 14 years.

Source: Sexual Offences Act 2003

\section{Section 30 case law}

Several Section 30 cases have been reviewed by higher courts with regard to the punishment imposed from the original case. In doing so, certain key issues contained within the constituents of the offence have been elucidated.

\section{Hulme v. Director of Public Prosecutions}

In dismissing an appeal for the original sentence convicting the applicant of a Section 30 offence, the High Court in this case $^{7}$ analysed the main issue as to whether the victim "was unable to refuse sexual touching because of, or for a reason related to, her mental disorder'.

The victim was a 27-year-old woman who had cerebral palsy and whose mental age was 'well below her chronological age'. It was not in dispute that she had a mental disorder within the meaning of the Mental Health Act 1983 and hence Section 30 of the Sexual Offences Act 2003 could 
potentially apply. She lived with her parents, who were licensees of a public house. The applicant was a man aged 73 years who met the victim in the bar of the public house. He was found to have touched the victim's vagina over her clothing and to have put her hand on his flaccid penis which was outside his trousers. The court was 'unsurprisingly satisfied that the touching was of a sexual nature'. The applicant admitted he had kissed the victim, stroked her hair and held her hand, but denied any other physical contact. He was aware of her intellectual impairment. His appeal centred upon whether the victim had the capacity to refuse the sexual touching because of her mental disorder.

The original judgment concluded that the victim lacked the necessary capacity and found she was a 'vulnerable lady of limited mental ability or capacity' who had 'a mental capacity well below her actual age and...was childlike, naïve'. The court was satisfied that she 'understood the nature of sexual relations but... did not have the capacity to understand that when placed in a situation of being touched sexually... she could choose not to agree to it.' An important aspect elucidated was that the victim was able to say 'no' to the applicant when he asked her whether 'she wanted him'. The court opined that she was 'saying no to sexual intercourse which was the question being put to her by the appellant and not to whether she agreed to being touched in the way that he was touching her and placing her hand on his penis', and that she was incapable of stopping the applicant from carrying out sexual activity with her due to her mental disorder. The High Court further summed this up by saying that although the victim did not want him to act in the way he did, 'she was unable effectively to communicate her choice' to the applicant. The victim was able to give evidence that when the applicant touched her 'she did not know what to do or say, although it made her feel sad, hurt and upset', and that 'she was not able effectively in those circumstances to communicate her wishes to him in the way that any woman of her age, not suffering from her disabilities, would have done in similar circumstances.'

This case demonstrates an important aspect which clinicians may face when assessing capacity in such cases. Many people, even those with dementia or an intellectual disability, where they are able to converse, if asked directly would probably be able to say 'no' to an unfamiliar person requesting sexual intercourse. However, they are still very vulnerable to being surreptitiously 'groomed' by others with the intention of performing inappropriate sexual activity. Conversely, they are equally vulnerable to spontaneous opportunistic acts.

\section{$R$ v. C}

In overturning a Court of Appeal decision, the House of Lords judgment in $R v . C^{8}$ provided clarity as to the scope of the words 'unable to communicate' in Section 30(2)(b) of the Sexual Offences Act 2003 while also considering some aspects of capacity to consent to sexual activity. In overturning an original conviction decision, ${ }^{9}$ the Court opined that the victim's irrational fear due to her mental disorder could not be equated with a lack of capacity to choose, and there was no evidence that she was physically unable to communicate any choice that she had made. The Crown appealed against this decision on the grounds that, due to a misreading of Section 30 in general and of the words 'for any other reason' in particular, it wrongly narrowed the protection for people who have a mental disorder impeding their choice as to whether or not to engage in a sexual activity.

The victim in this case was a 28 -year-old woman with an established diagnosis of schizoaffective disorder; emotionally unstable personality disorder; an IQ of less than 75; and a history of alcohol misuse. She had previously been admitted to hospital on four occasions, three of which included detention under the Mental Health Act 1983. Following a hospital admission, she was discharged to a hostel. A couple of weeks later her community mental health team had concerns over her increasingly paranoid mental state. The woman was seen by a forensic psychiatrist, who noted her to be in an agitated and distressed state but she walked out of the interview. Soon after she met the defendant, who offered to help her, and she accompanied him to his friend's house. She was asked by the defendant to engage in oral sex on him. The woman gave evidence that she became panicky and afraid and wanted to get out of the house but did not do so as she feared for her life, and subsequently sexual activity occurred. Her treating psychiatrist gave evidence that given the deterioration in her mental state before the alleged events, her presentation during the interview with the forensic psychiatrist, her intellectual disability and impaired intellectual functioning, and her highly aroused state, she would not have had the ability to consent to sexual contact at the time of the alleged offence. The defendant was subsequently charged under Sexual Offences Act Section 30.

Whereas there was much discussion regarding assessment of capacity under the Mental Capacity Act 2005, the judgment noted that Section 30 is only concerned with people who are 'unable to refuse because of or for a reason related to a mental disorder' (Section 30(1)(c)), and that this inability may involve either the inability to choose (Section $30(2)(a))$ or the inability to communicate the choice made (Section 30(2)(b)). The judgment considered that it was 'quite clear that in the 2003 Act Parliament had in mind an inability to communicate which was the result of or associated with a disorder of the mind' and there was 'no warrant at all for limiting it to a physical inability to communicate. It must include a person with such a degree of learning difficulty that they have never acquired the gift of speech, so that it is impossible to discover whether or not they can understand or make a choice.' The judgment further commented that the words 'for any other reason' within Section 30(2)(a) 'are clearly capable of encompassing a wide range of circumstances in which a person's mental disorder may rob them of the ability to make an autonomous choice, even though they may have sufficient understanding of the information relevant to making it. These could include the kind of compulsion which drives a person with anorexia to refuse food, the delusions which drive a person with schizophrenia to believe that she must do something, or the phobia (or irrational fear) which drives a person to refuse a life-saving injection (as in $R e M B^{10}$ ) or a blood transfusion (as in NHS Trust v. $T^{\mathrm{ll}}$ ).' (Other reasons 
why a person may be unable to refuse might include not understanding that they had a choice due to remaining in hospital or residential treatment, or because they had a condition that might affect the ability to make a choice. ${ }^{4}$ ) The House of Lords accepted that because of her mental capacity, the victim was unable to refuse sexual activity due to an irrational fear of what was happening to her at the time 'arising from her mental disorder or such confusion of mind arising from her mental disorder' (in essence, a person who has a mental disorder might be capable of exercising choice in one situation but not in another, depending on contextual factors). Similarly, she was considered unable to refuse because of her mental disorder as she was 'unable to communicate such a choice...even though she was physically able to communicate' - the inability to communicate the choice within Section 30(2)(b) was not strictly limited to physical inability alone.

\section{Discussion}

Baroness Hale encapsulated the issue of capacity and sexual activity when she stated in $R$ v. $C$ [2009]: 'it is difficult to think of an activity which is more person and situation specific than sexual relations. One does not consent to sex in general. One consents to this act of sex with this person at this time and in this place. Autonomy entails the freedom and the capacity to make a choice of whether or not to do so.' She considered such an approach 'entirely consistent with the respect for autonomy in matters of private life which is guaranteed by Article 8 of the European Convention on Human Rights', and indeed full account of the Convention was taken and core aspects incorporated into the Sexual Offences Act 2003. ${ }^{1}$ She further noted that the important object of the Act was 'to get away from the previous "status" based approach which assumed that all "defectives" lacked capacity, and thus denied them the possibility of making autonomous choices, while failing to protect those whose mental disorder deprived them of autonomy in other ways.' The Sexual Offences Act 1956 was noted to have failed in a variety of ways to achieve an appropriate balance for dealing with people with mental disorders. ${ }^{12}$ For example, the specialist offences only protected a person who had severe intellectual disability (i.e. was a 'defective') and not any person with a different mental disorder; some apparently protective sexual offences were overinclusive as they solely relied on status (i.e. whether the person was a 'defective') and not functional ability (i.e. whether the person was capable of deciding whether or not to have sexual intercourse); and the reference to 'defective' was criticised as demeaning and derogatory.

Of the cases reaching the courts, the most common group particularly vulnerable to Section 30 offences are people with intellectual disabilities, ${ }^{13-15}$ but cases involving people with dementia, ${ }^{5}$ depression $^{6}$ and post-stroke disability and cognitive impairment ${ }^{16}$ have also been reported. The necessary combination of the offender having an awareness of the victim's mental disorder, and having known or been reasonably expected to have known that the victim was likely to be unable to refuse, means that the offence may well be prosecuted more regularly where the victim has a intellectual disability than any other form of mental disorder. This is because the effect on capacity is more likely to be apparent to anyone where someone has this type of mental disorder due to external distinguishing features that might indicate the presence of a mental disorder. $^{12}$ Although the vast majority of offences are committed by men on vulnerable women with mental disorders, it is obviously possible for the reverse to occur and for same-sex offences to happen (see Jones, ${ }^{17}$ where a 19-year-old man with Down syndrome and a mental age of 5 years was sexually assaulted by a 52 -year-old male). It is perfectly possible that people with psychotic, hypomanic or manic disorders are equally as vulnerable to these offences, especially if sexualised or disinhibited behaviour is part of their presentation. The burden of proving whether the defendant knew or could reasonably have known the victim had a mental disorder, and that, because of this or for a reason related to it, the victim was unable to refuse, lies with the prosecution. In some cases it may be difficult to establish that the defendant could reasonably be expected to have relevant knowledge, especially in cases where there are no external distinguishing features that might indicate mental disorder and the defendant had no pre-existing knowledge of the alleged victim. ${ }^{12}$

For the clinician requested to submit an expert report or statement for Section 30 offences the key areas to address are outlined in Box 3. In particular, consideration needs to be made of simplifying language and explanations of medical terms because evidence may also need to be given in court in front of a jury. An important area to elucidate is how the alleged offender could have known that the alleged victim had a mental disorder which affected their decision-making ability. The core issue of capacity should be described specifically in terms of the definition in Section 30(2)(a). It is important to remember that capacity to consent to sexual relations is issue-specific and not partner-specific. The test of capacity under the Mental Capacity Act (as in Box 3) can provide structure for this capacity assessment and reasoning in relation to the offence. A legal test for assessing capacity to consent to sexual relations could similarly be used in assessments and

Box 3 Key issues for clinicians to address for Section 30 assessments and reports ${ }^{a}$

- Does the alleged victim have a mental disorder?

- Could the alleged offender know or reasonably be expected to know the alleged victim has a mental disorder?

- Could the alleged offender have known or reasonably be expected to have known the alleged victim was likely to be unable to refuse because of the mental disorder?

- Does the victim lack capacity to choose whether to agree to the touching?

- Can the alleged victim communicate their decision to the alleged offender?

a. An extended version of this test of capacity is available as an online supplement to this paper. 
reports. The test arises from $X$ City Council v. $M B, N B$ and $M A B^{18}$ (see also Local Authority $X v$. (1) $M M$ (2) $K M,^{19}$ a case involving a woman with moderate intellectual disability and paranoid schizophrenia) and considers whether the person had:

- sufficient knowledge and understanding of the nature and character - the sexual nature and character - of the act of sexual intercourse

- sufficient knowledge and understanding of the reasonably foreseeable consequences of sexual intercourse

- the capacity to choose whether or not to engage in the act

- the capacity to decide whether to give or withhold consent to sexual intercourse (and, where relevant, to communicate their choice to their spouse).

Another area related to Section 30 offences where expert opinion may be needed is psychiatric assessment of the actual offenders. Often an offender is an older male with apparent first-time offence. Although this could be as yet unmasked recidivist behaviour, it could potentially be part of a mental disorder itself, for example, an early dementia contributing to inappropriate behaviour. Psychology assessment may also be requested or needed as part of the assessment of the alleged victim, ${ }^{13}$ and opinions may be requested as part of the sentencing process as to the medium- or long-term psychological impact to the victim with a pre-existing mental disorder. ${ }^{20}$ In practice, the Sexual Offences Act 2003 may, at times, be considered difficult to implement. This is because in some people with a mental disorder their capacity could fluctuate such that it may be difficult to prove what their mental state was at the time of an alleged offence (i.e. while conducting retrospective assessments of capacity). ${ }^{21}$ Nonetheless, knowledge of Section 30 and its implementation will aid psychiatrists of all specialties, should they be required to provide evidence in court.

\section{Acknowledgement}

We thank Mr Ben Player.

\section{About the authors}

Martin Curtice is consultant in old age psychiatry, and Emma Kelson is ST5 in old age psychiatry, Juniper Centre, Moseley Hall Hospital, Birmingham and Solihull Mental Health NHS Foundation Trust, Birmingham, UK.

\section{References}

1 Home Office Communication Directorate. Setting the Boundaries: Reforming the Law on Sex Offences, Volume I. Home Office, 2000.

2 Home Office Communication Directorate. Consultation Paper on the Review of Part 1 of the Sex Offenders Act 1997. Home Office, 2001.

3 Home Office. Protecting the Public: Strengthening Protection against Sex Offenders and Reforming the Law on Sexual Offences (Cm 5668). TSO (The Stationery Office), 2002.

4 Home Office. Guidance on Part 1 of the Sexual Offences Act 2003. Home Office Circular 2004; 021 (http://www.homeoffice.gov.uk/aboutus/home-office-circulars/circulars-2004/021-2004/)

5 R v. Perera (Harry Maximus) [2007] EWCA Crim 3277 (CA (Crim Div)).

$6 R$ v. Bradford (Christopher) [2006] EWCA Crim 2629 (CA (Crim Div)).

7 Hulme v. Director of Public Prosecutions [2006] EWHC 1347 (Admin).

8 R v. C [2009] UKHL 42.

$9 R$ v. C [2008] EWCA Crim 1155

10 Re MB (Medical Treatment) [1997] 2 FLR 426.

11 NHS Trust v. T (adult patient: refusal of medical treatment) [2004] EWHC 1279 (Fam).

12 Stevenson K, Davies A, Gunn M. Blackstone's Guide to the Sexual Offences Act 2003. Oxford University Press, 2004.

13 Attorney General's Reference (No.106 of 2005), Re [2006] EWCA Crim 510.

14 Attorney General's Reference (No.75 of 2007), Re [2007] EWCA Crim 2266 (CA (Crim Div)).

15 R v. D (Donald David) [2005] EWCA Crim 1459 (CA (Crim Div)).

16 R v. Adcock (Peter) [2010] EWCA Crim 700 (CA (Crim Div)).

17 Jones (David William) [2006] 2 Cr App R (S) 18

$18 \times$ City Council v. MB, NB and $M A B$ (by his litigation friend the Official Solicitor) [2006] EWHC 168 (Fam).

19 Local Authority $X$ v. (1) MM (by her litigation friend the Official Solicitor) (2) KM [2007] EWHC 2003 (Fam).

20 Selfe D. Sentencing of persons with mental disorder. Crim Lawyer 2008 184: $2-5$.

21 Lovett K. Sexual abuse of patients by psychiatrists (letter). Psychiatr Bull 2006; 30: 352. 